\title{
Learning Skills Workshops Supporting First-Year Courses
}

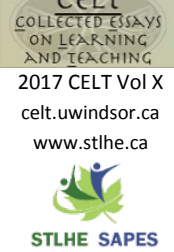

\author{
Sheilagh Grills \\ Brandon University
}

DOI: $10.22329 /$ celt.v10i0.4744

Student Services support, including learning skills assistance, can be integral in empowering learners. First-year students are expected to be self-directed in their learning, yet may have neither been challenged nor experienced negative consequences for a lack of perseverance. Academic skills professionals can be partners with teaching faculty in student success by helping to build transferable learning skills, especially for high-fail introductory courses. In this paper, I report on supplementary workshops developed to target fundamental skills with course-specific examples. This partnership included incentivizing academic support with both carrots and sticks; instructors in introductory biology strongly urged students receiving D grades or below on the first test to approach Student Services for support, while sociology faculty incorporated workshop attendance into the introductory course with participation grades. Following such incentivizing of learning skills, workshop attendance increased by 45\%. In both courses, first test scores and high school averages for students attending workshops did not differ from students not attending workshops. However, students who attended learning skills workshops had significantly higher course grades, persistence, sessional grade point averages (GPAs), and cumulative GPAs than students not attending workshops. Controlling for high school average, each learning skills workshop attended was associated with a 0.11 to 0.27 increase in sessional GPA on a 4.3 point scale.

W hile academic support has a long history within Canadian post-secondary institutions (Gilbert, Chapman, Dietsche, Grayson, \& Gardner, 1997), learning skills workshops may be seen as tangential by both faculty and students (Tait \& Entwistle, 1996). This paper describes a partnership between Student Services and faculty teaching highfail introductory courses at a small primarily undergraduate university on the Prairies. Through dialogue with instructors, I used targeted workshops to combine transferable, fundamental skills with course-specific examples. Faculty 'incentivized' attendance to encourage students to identify workshops as a series for multiple opportunities for relationship-building and engagement. This cooperative endeavour between faculty and Student Services emphasizes the importance of both partnerships in student success, and assessment measures for academic support services beyond simple utilization data (Keeling, Wall, Underhile, \& Dungy, 2008).
First-year students need to be self-directed in their learning, yet Côté and Allahar (2007) argue that direct-entry learners may not have been challenged in high school, or may not have experienced negative consequences for a lack of perseverance. Among those expressing concern, Slavin (2007) argues that a reliance on teaching to standardized testing has decreased thinking skills and emphasized memorization. Changes in the student population include more goal-directed students focused on education as a means to specific careers, shifts in the knowledge economy and more grade-focused students who eschew trial and error learning (Frost \& Connolly, 2016). Professional designations have increased, yet some of the highest failure rates occur in pre-professional programs (Kirby, 2007).

Academic support within Student Services is centered on student learning research and approaches to learning and studying (Biggs, 1987). Institutions may embed specialized academic skills staff within faculties or schools, utilize a learning commons 
approach, or have generic learning support within an Academic Skills Centre. Regardless of centralization, learning skills staff can help with the disparity between the target understandings of instructors and the actual understandings reached by students (Entwistle, McCune, \& Hounsell, 2002).

Student affairs and services arose from the roots of constructivist learning theory, and while academic support may take many forms, the goal of general learning skills support is increased selfregulation of learning or metacognition. Affective factors such as self-efficacy and motivation both influence and are influenced by self-regulated learning (Egan, 2011). In some cases, students may need to 'unlearn' previous surface approaches to learning that may have served them well in high school. Teaching metacognitive knowledge or awareness of perceived knowledge supports students' learning and helps them develop expertise (van Velzen, 2012). Expert students approach particular learning tasks differently based on task demands. In contrast, first-year students often lack both this selfawareness and the knowledge of fundamental learning strategies.

But it is not only first-year students who may have a less than successful approach to learning. The way in which students process information and their intent in approaching the task is closely related to the quality of outcome in learning. When students perceive material as uninteresting but are anxious and threatened about performance, they are more likely to adopt a surface approach to learning (Marton \& Säljö, 1997). A surface approach to learning is more passive and characterized by a reliance on memorization of details, while a deep approach is more holistic and characterized by trying to understand the ideas or meaning of a text. Courses that are less preferred or are perceived to cover an excess of information are associated with surface approaches to learning (Baeten, Kyndt, Struyven, \& Dochy, 2010). Students who are driven to avoid failure or are otherwise externally motivated are more likely to adopt a surface approach (Berglas \& Jones, 1978; Thomas \& Gadbois, 2007). In the face of this description of students, teaching academic skills is like setting up 'traps of engagement' or situations where some learning is almost inevitable if students are cognitively present (Cowan, 1998). Effective learning skills workshops involve repeated interactions that help first-year students build connections for retention and success (Grills, 2009). MacNeil, Wood, Zivcakova, Glover, and Smith (2014) had success with using Learning Task Inventories for specific units in Organic Chemistry to encourage metacognitive skills, but still had the recurring issue of students' underutilization of resources.

\section{Incentivizing Academic Support}

In a large-scale study of Australian students, Paloyo, Rogan, and Siminski (2016) explored an inducement effect on academic support, in this case, Peer Assisted Study Sessions (PASS). Students in 14 introductory courses were randomly assigned to control and incentivized groups. While all students had access to academic supports for the class, those in the incentivized group were entered into a lottery for gift cards if they attended the PASS sessions. The incentive was contingent only on attendance rather than student performance outcome, "thus it is not likely that the lottery can increase, say, student motivation (and hence, student outcomes) unless it was through increased PASS attendance" (p. 17). Students in the incentivized group were less likely to attend zero sessions and more likely to attend eight or more sessions, even though the threshold for entry into the lottery was five sessions. In one term the value of the gift cards available was considerably larger than another term, yet the attendance was similar at approximately $19 \%$ higher for the incentivized group. It is important to note, however, that this inducement effect was centered on students from lower socioeconomic background areas. Paloyo et al. (2016) concluded that one hour of academic support improved course grades for the overall group by 0.065 standard deviations or 1.26 marks on a 100-point scale, which was not significant due to large variation. 


\section{The Study}

Generic academic skills workshops address fundamental transferable learning and success skills for entering and returning students such as organization, time management, note-taking in lectures, reading textbooks effectively, summarizing and elaboration skills, test preparation, exam strategies and memory skills. These sessions are typically optional and non-credit bearing. The targeted workshops described in this paper are directed at high-fail entry level courses required to proceed in further studies within the discipline. Such gate-keeper courses are often perceived by students to have more demands and a higher workload, and thus are more likely to have students using a surface approach to learning.

Targeted workshops adapt the transferable skills from the generic workshops using coursespecific materials. In cooperation with teaching faculty, I developed course-specific materials based on a task analysis of the demands of the course, question styles used by instructors for evaluation, ideal response samples, and recommended study strategies. For example, the generic workshop on multiplechoice strategies was adapted to use only potential test questions on material covered in the targeted course while the general note-taking workshop demonstrated active listening, recording, and connecting ideas from course lecture slides. Similarly, the generic memory strategies workshop presented the same transferable skills of encoding through summarizing, reorganizing, and rehearsing material, but all mnemonic examples were taken from lectures or textbooks used in the targeted course.

In preliminary offerings, these workshops targeted pre-professional programs including courses in Human Anatomy \& Physiology, Biology, Sociology, Psychology, World History, and Music History. In the 2013-2014 academic year, learning skills workshops serviced 504 students in an institution with 2740 undergraduate learners (18\%). The following year faculty and Student Services partnered to try and be more directive in getting students to workshops. In introductory biology, instructors strongly urged students receiving D grades or below on the first test to approach Student Services for support. Students in the introductory sociology courses received 5\% participation marks for attending at least four learning skills workshops throughout the semester. For the 2014-15 year, total workshop attendance increased to 714 participants with a population of 2671 undergraduates (27\%). Information was collected in accordance with TCPS2 (Canadian Institutes of Health Research, Natural Sciences and Engineering Research Council of Canada, \& Social Sciences and Humanities Research Council of Canada, 2014, p. 18) guidelines for program evaluation activities used for improvement purposes (Article 2.5).

\section{Results: Introductory Biology}

First-year biology is a gate-keeper course for further studies in biology, as well as pre-professional programs in nursing, medicine, dentistry, and medical technologies. In the second term of 2013, the instructor for the preparatory or remedial biology class that marginal students must complete before their first attempt at introductory biology, invited me into the class. Working with the instructor, we demonstrated how to prepare study questions from the text, how to take more effective notes, and organization strategies for memory. This was the preliminary work for the targeted workshops the next academic year. In the first term of 2014, instructors informed the class that those receiving a $\mathrm{D}$ grade $(50$ $59 \%$ ) or less on the first test would be referred to Student Services for support and intervention. Faculty released the list of students who were unsuccessful on the first unit test and Student Services sent an electronic communication to each member of this cohort. The personalized message included information on available supports including the targeted learning skills workshops.

Of the 118 students on this list, 70 did not use learning skills while 48 attended at least one workshop. The average first unit test mark for students receiving a $\mathrm{D}$ or less was $45.57 \%(S D=$ 


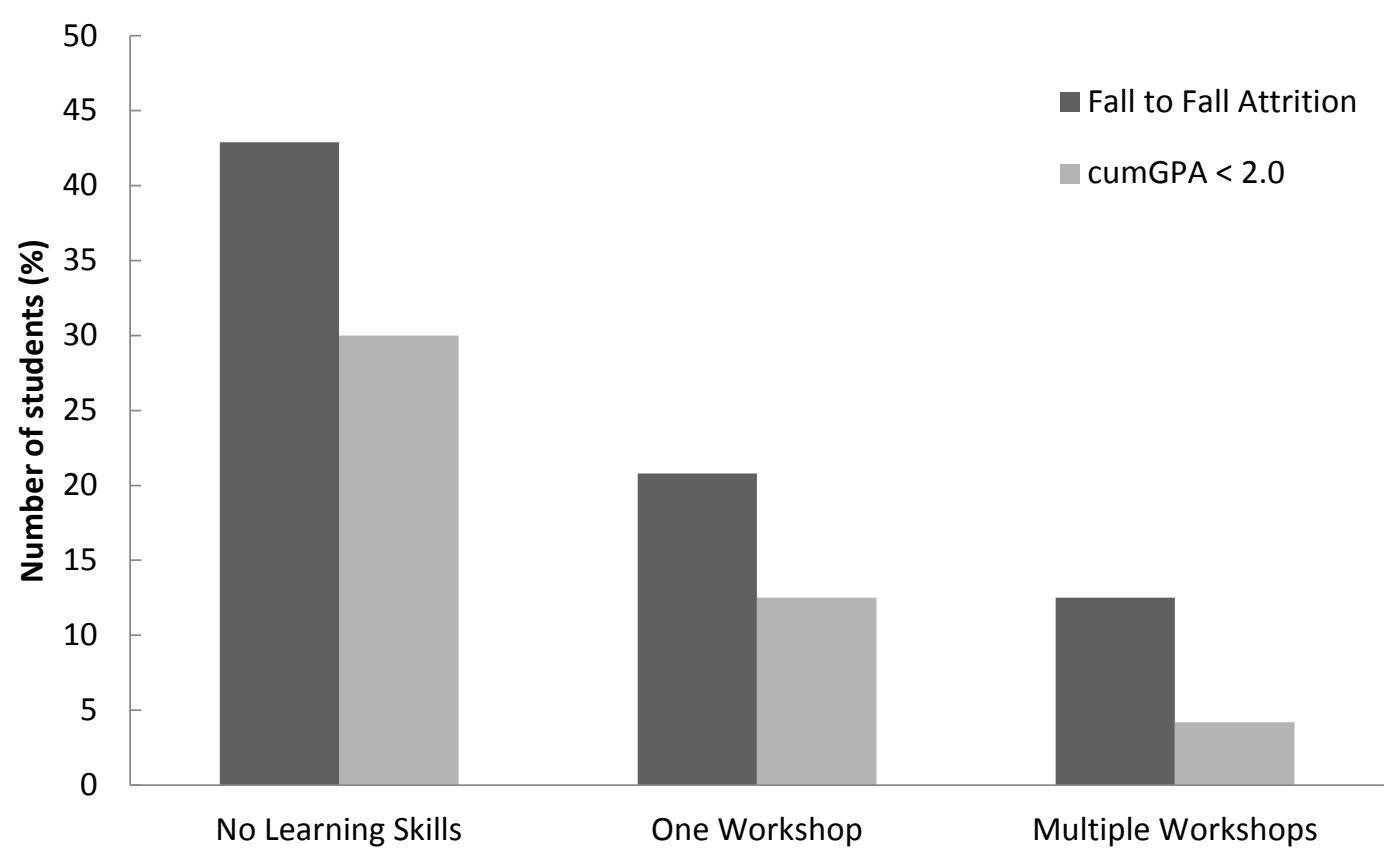

Figure 1

Percentage of introductory biology students not returning to studies the next Fall term (Fall to Fall Attrition), and percentage of leavers with cumulative GPAs below 2.0 (cumGPA <2.0) who either did or did not attend one or more learning skills workshop

10.43), but there was no difference between those attending learning skills workshops and those not attending, $t(116)=1.62, p=.11$. High school grades were equivalent for this cohort $(M=78.37 \%, S D=$ 8.34) and the overall incoming cohort high school average for the institution was $77.30 \%$. There were no significant differences in high school averages for those who attended no sessions $(M d n=77.40 \%, S E$ $=1.06, n=58)$, those who attended one workshop $(M d n=81.80 \%, \mathrm{SE}=1.60, n=21)$, and those who attended multiple workshops $(M d n=81.25 \%, S E=$ $1.78, n=22$ ), Kruskal-Wallis $H(2)=3.91, p=.14$ (as the workshop attendance groups were unequal in size, the nonparametric analog of a one-way analysis of variance was used).

Attrition was examined both in terms of fallto-fall rates and by academic performance as measured by grade point average for leavers (Figure 1). Not only were there lower attrition rates for workshop participants, but leavers who attended workshops had a higher cumulative GPA (2.33 and 2.31 compared to 1.91 for non-attenders) and so were more likely to have left for personal reasons rather than have been removed for poor academic performance.

However, the three attendance groups had unequal participants ( $n=70,24$ and 24 respectively), and there were comparatively more students with unknown high school grades in the group who chose not to attend academic support sessions. Unknown high school averages are more typical for learners who completed a General Education Development (GED) test or were admitted as mature students.

The comparison between groups of students who attend academic support sessions and those who do not are impacted by self-selection bias, in which pre-entry characteristics such as prior academic performance and motivation factors may figure. Yet de Boer, Donker, and van der Werf (2014) found no difference in learning interventions where "students or classes were randomly assigned to the experimental and control groups and those without random assignment" (p. 529). They suggest that this is because the experimental and control groups in their meta-analysis were matched on pre-test differences.

With this in mind, I used high school grades to match the larger group of students who did not 
attend workshops with those who did attend learning skills, and randomly selected for two groups of 48 students. Persistence measures on these two groups showed that more students who attended at least one learning skills workshop continued into the next year of studies $(81 \%)$ than those not using this form of academic support (58\%), $\chi^{2}(1, N=96)=5.978, p=$ 0.014 . In terms of academic performance, those who did not attend workshops had a lower sessional or yearly grade point average on a 4.3 scale $(M=1.76$, $S D=0.92)$ than those who did make use of this service $(M=2.18, S D=0.86), t(94)=2.338, p=$ 0.022 . Students who did not attend workshops also had a significantly lower cumulative grade point average after two years of study $(M=1.93, S D=0.93)$ than those who did use learning skills support $(M=$ 2.32, $S D=0.80), t(94)=2.192, p=0.031$.

Regression analysis of sessional GPA using the matched groups indicated that the addition of learning skills attendance into the model was a small but significant increase in the variability accounted for by high school average alone (Table 1). When prior academic performance as measured by high school average is held constant, for every one learning skills workshop attended, we can expect a 0.11 increase in the sessional GPA (on a 4.3 scale).

\section{Results: Introductory Sociology}

First-year sociology is preparation for continuing work within sociology as well as pre-professional programs in social work, nursing, and justice studies. Class participants were offered the carrot incentive of a $5 \%$ participation grade if they attended four or more workshops during the term. With the cooperation of two instructors, I examined workshop attendance for a total of 191 students with $59 \%$ of the cohort attending at least one session. There was no relationship between workshop attendance and either first test scores $(r=-0.061, p>0.05)$ or high school average $(r=0.051, p>0.05)$.

There were no significant differences in prior academic performance as measured by high school average percentages for students not attending workshops $(M=78.34, S D=8.86, n=67)$, those attending "some" workshops as defined by one to three sessions $(M=81.32, S D=7.19, n=31)$, and those attending "most" workshops as defined by at least four of five sessions required to get the participation bonus $(M=79.58, S D=8.74, n=68)$, $F(2,163)=1.32, p>0.05$. Workshop attendance significantly predicted final course grade in introductory sociology $(t(161)=7.015, p<0.001)$.

Table 1

Regression table for sessional GPA in introductory biology

\begin{tabular}{llrrr}
\hline & & $\mathrm{B}^{\dagger}$ & SE-B & $\beta$ \\
\hline Step 1 & & & & \\
& Constant & -3.181 & 0.927 & $0.519^{* *}$ \\
& High-school average & 0.064 & 0.012 & \\
Step 2 & & & \\
& Constant & -3.040 & 0.910 & $0.492^{* *}$ \\
& High-school average & 0.061 & 0.010 & $0.197^{*}$
\end{tabular}

$R^{2}=0.269$ for Step $1, \Delta R^{2}=0.038$ for Step $2(p<0.05) .{ }^{*} p<0.05,{ }^{* *} p<0.001$, students with unknown high school averages removed from analysis $n=86 .{ }^{\dagger} \mathrm{B}=$ unstandardized coefficient; $\mathrm{SE}-\mathrm{B}=$ standard error of the unstandardized coefficient; $\beta=$ standardized coefficient. 


\section{Table 2}

Regression table for course grade in introductory sociology

\begin{tabular}{llrll}
\hline & $\mathrm{B}^{\dagger}$ & SE-B & $\beta$ \\
\hline Step 1 & & & \\
& Constant & -2.151 & 0.815 & \\
& Test One scores & 0.075 & 0.015 & $0.352^{* *}$ \\
& High-school average & 0.048 & 0.011 & $0.309^{* *}$ \\
Step 2 & & & \\
& Constant & -2.418 & 0.717 & $0.392^{* *}$ \\
& Test One scores & 0.083 & 0.013 & $0.272^{* *}$ \\
& High-school average & 0.042 & 0.010 & $0.406^{* *}$ \\
& Learning skills workshops & 0.265 & 0.038 & \\
\hline
\end{tabular}

$\mathrm{R}^{2}=0.304$ for Step $1, \Delta \mathrm{R}^{2}=0.163$ for Step $2(p<0.001), * * p<0.001$, students with unknown high school averages removed from the analysis, $n=165 .{ }^{\dagger} \mathrm{B}=$ unstandardized coefficient; SE-B = standard error of the unstandardized coefficient; $\beta=$ standardized coefficient

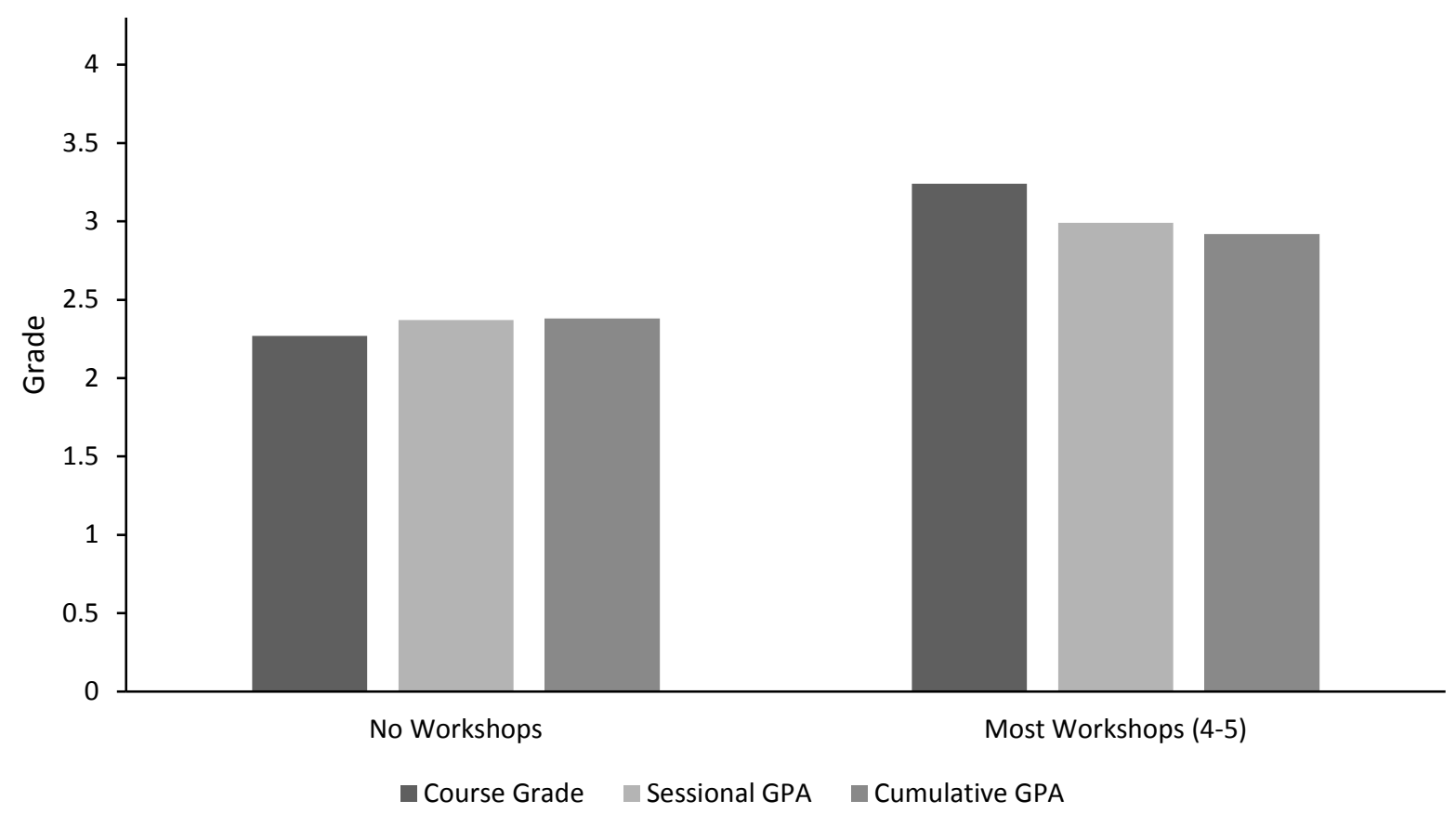

Figure 2

Academic performance in introductory sociology by workshop attendance. ${ }^{1}$

\footnotetext{
${ }^{1}$ Introductory sociology course grade was significantly higher for workshop attendees, $p<0.001$, Sessional GPA was significantly higher for workshop attendees, $\mathrm{p}<0.001$, and Cumulative GPA was significantly higher for workshop attendees, $p<0.01$. Grades are on a scale of 0 - 4.3.
} 
Students who did not attend learning skills workshops ended the course with a significantly lower course grade than those who attended most workshops, Mann Whitney $U=1492.50, z=-0.5725$, $p<0.001, r=-0.46$ (medium effect size; nonparametric measure was used as the variance of the groups was not homogeneous). When high school average and test one scores are held constant, for every one learning skills workshop attended, we can expect a 0.27 increase in course grade on a 4.3 point scale (Table 2).

There was significant variability in both the sessional GPA for students not attending workshops $(M=2.37, S D=1.14, F(2,188)=4.692, p=0.01)$, and in the cumulative GPA of non-attenders $(M=$ $2.38, S D=1.10, \mathrm{~F}(2,188)=4.205, \mathrm{p}=0.02)$. Therefore, I compared the academic performance of students not attending workshops $(n=79)$ and those attending 'most' workshops (four or five sessions, $n=$ 79) non-parametrically.

The sessional GPA for students not attending workshops $(M d n=2.66, S E=0.13)$ was significantly lower than for students attending most learning skills workshops $(M d n=3.06, S E=0.10)$, Mann Whitney $U=2113, z=-3.50, p<0.001$ (Figure 2). Attendance at learning skills workshops significantly predicted grade point average for the year on a 4.3 scale $(t(163)=4.24, p<0.001)$. When high school average is held constant, for every one learning skill workshop attended, we can expect a 0.15 increase in sessional GPA.

Finally, the cumulative GPA for students not attending workshops $(M d n=2.67, S E=0.12)$ was significantly lower than for students attending most learning skills workshops $(M d n=2.97 S E=0.09, U$ $=2221, z=-3.13, p<0.01)$. Cumulative GPA was also predicted by workshop attendance $(\beta=0.246, t$ $(163)=3.85, p<0.001)$. When high school average is held constant, every two learning skills workshops attended was associated with a 0.248 increase in cumulative GPA on a 4.3 point scale.

\section{Discussion}

Much of Student Services work is done behind the scenes in post-secondary institutions. The work of student affairs professionals is central to retention and engagement but may be viewed as lacking robust assessment measures. My aim in this study was to advance our understandings of the relative contributions of prior academic performance and learning skills support in attempting to frame our impact measures. While grades are often viewed as outcome measures for students' cognitive effectiveness, they can also be tools for addressing institutional effectiveness (Keeling et al., 2008). High school average and first test results give an indication of students' work prior to accessing learning support from Student Services.

In this study, all students were encouraged but not required to attend learning skills workshops which were redesigned to reflect specific course materials, design, and evaluation. Faculty described academic support services in their first-year classes, and directed students to workshops either proactively with bonus participation marks in the case of sociology, or more reactively after an unsuccessful first test in the case of biology. Workshop attendance was higher (59\% of the class) with the positive reinforcement of bonus marks, while $41 \%$ of the biology class followed the instructor directive. It would be interesting to compare these participation rates with previous years without faculty actively encouraging attendance; however, this was not possible in this study due to lack of access to prior course records.

Across two very different introductory courses, learning skills workshop attendance was a significant predictor of student success. Students who attended learning skills workshops targeted for gatekeeper introductory courses ended the class with higher final grades, had higher sessional grade point averages, and higher cumulative GPAs. When high school average was held constant, every learning skills 
workshop attended was associated with a 0.11 to 0.27 increase in sessional grade point average. In future work, measuring academic performance with course grades on a percentage scale would provide more precision than using grade point averages.

For both courses, there was no relationship between first test scores and workshop attendance. Nor could workshop attendance be predicted by prior academic performance as measured by high school grades. It was not the case that marginal students were more likely to seek support, nor were scholarship contenders more likely to embrace the bonus mark incentive. Prior academic performance was inadequate to explain students' subsequent decisions to make use of the optional but incentivized learning skills workshops. As the workshops became viewed as a series - the Success Series - rather than isolated single issue 'repair sessions', they became part of the campus culture and were less likely to be viewed in remedial or punitive terms. Perhaps a survey of the entire targeted class or a review of campus-wide questionnaires (e.g., National Survey of Student Engagement) would be informative to further explore issues in the students' decision matrix.

The fall to fall attrition rate for introductory biology students decreased from $42.9 \%$ for students not attending workshops after a poor performance on the first test, to $20.8 \%$ for students attending one workshop, down to $12.5 \%$ for students attending multiple workshops. Additionally, workshop participants who did not return to studies had a higher cumulative grade point average than nonparticipants, suggesting they were less likely to have been forced to leave by the institution due to poor academic performance. For future research, I would suggest workshop participants be interviewed to provide more qualitative information about reasons for leaving.

As more than thirty years of research has shown us, students enter post-secondary studies with a variety of inputs or attributes, which when combined with institutional experiences produce learning and/or leaving (Pascarella \& Terenzini, 2005). Astin's career (1996) has focused on the importance of student involvement in predicting retention and success, while others emphasize early contact and building connections (Tinto, 1993), or more simply, engagement (Kuh et al., 2005).

It is problematic to draw conclusions about students' motivations and attendance at learning skills workshops when working from quasiexperimental studies in naturalistic settings with interlaced influences. However, students who attend multiple workshops gain more of a personal understanding of available resources than do learners who read about the Academic Skills Centre in orientation brochures. Knowing about academic support may help to reframe past performance in terms of controllable, unstable reasons which can be changed for the future (Weiner, 1986). Learning skills workshops incorporate active learning about specific tasks in the targeted course, with prompt feedback. Faculty express their high expectations of students when encouraging workshop participation in order to be more successful in their courses. The student-workshop leader contact is less formal than classroom experiences yet still regularized through weekly available sessions. Thus, the learning skills workshops encourage students to devote time and energy to purposive educational activities and follow the basic principles for good practice in undergraduate education (Chickering \& Gamson, 1987).

The cooperation and dialogue between faculty and Student Services discussed in this paper is but one way of directly involving teaching staff in student affairs programs and services. Levitz and Noel (1989) wrote almost thirty years ago, "a caring attitude of faculty and staff is the most potent retention force on campus" (p. 66). Learning skills workshops supporting first-year courses are an effective partnership of concerned professionals working together for increased students' success.

\section{References}

Astin, A. W. (1996). "Involvement in learning" revisited: Lessons we have learned. Journal of College Student Development, 37(2), 123134. VIEW ITEM 
Baeten, M., Kyndt, E., Struyven, K., \& Dochy, F. (2010). Using student-centred learning environments to stimulate deep approaches to learning: Factors encouraging or discouraging their effectiveness. Educational Research Review, 5(3), 243-260. VIEW ITEM

Berglas, S., \& Jones, E. E. (1978). Drug choice as a self-handicapping strategy in response to noncontingent success. Journal of Personality and Social Psychology, 36(4), 405-417. VIEW ITEM

Biggs, J. (1987). Student approaches to learning and studying [Monograph]. Melbourne: Australian Council for Educational Research. VIEW ITEM

Canadian Institutes of Health Research, Natural Sciences and Engineering Research Council of Canada, and Social Sciences and Humanities Research Council of Canada, Tri-Council Policy Statement: Ethical Conduct for Research Involving Humans, $2^{\text {nd }}$ edition (TCPS2) December 2014. VIEW ITEM

Chickering, A. W., \& Gamson, Z. F. (1987). Seven principles for good practice in undergraduate education. American Association for Higher Education Bulletin, 39(7), 3-7. VIEW ITEM

Côté, J. E., \& Allahar, A. L. (2007). Ivory tower blues: A university system in crisis. Toronto, $\mathrm{ON}$ : University of Toronto Press.

Cowan, J. (2006). On becoming an innovative university teacher: Reflection in action $\left(2^{\text {nd }}\right.$ ed.). Maidenhead, UK: McGraw-Hill Education.

de Boer, H., Donker, A. S., \& van der Werf, M. P. C. (2014). Effects of the attributes of educational interventions on students' academic performance: A meta-analysis. Review of Educational Research, 84(4), 509545. VIEW ITEM
Egan, R. (2011). Adjusting curricular design to "CREATE" a culture of self-regulation. The Canadian Journal for the Scholarship of Teaching and Learning, 2(2), Article 6. VIEW ITEM

Entwistle, N., McCune, V., \& Hounsell, J. (2002). Approaches to studying and perceptions of university teaching-learning environments: Concepts, measures and preliminary findings (Occasional Report 1). VIEW ITEM

Frost, G., \& Connolly, M. (2016). Is fine tuning possible with grade-focused students? Collected Essays on Learning and Teaching, 9, 147-154. VIEW ITEM

Gilbert, S., Chapman, J., Dietsche, P., Grayson, P., \& Gardner, J. N. (1997). From best intentions to best practices: The first-year experience in Canadian postsecondary education. [Monograph Series Number 22]. Columbia, SC: National Resource Center for The Freshman Year Experience \& Students in Transition. VIEW ITEM

Grills, S. (2009, July). A comparison of learning skills delivery models: Individual appointments, non-credit workshop and transitional success course. Paper presented at the International Conference on the First-Year Experience, Montreal, QC. VIEW ITEM

Keeling, R. P., Wall, A. F., Underhile, R., \& Dungy, G. J. (2008). Assessment reconsidered: Institutional effectiveness for student success. Washington, DC: National Association of Student Personnel Administrators.

Kirby, D. (2007). Reviewing Canadian postsecondary education: Post-Secondary education policy in post-industrial Canada. Canadian Journal of Educational Administration and Policy, 65, 1-24. VIEW ITEM

Kuh, G. D., Kinzie, J., Schuh, J. H., Whitt, E. J., \& Associates. (2005). Student success in college: 
Creating conditions that matter. San Francisco, CA: Jossey-Bass.

Levitz, R., \& Noel, L. (1989). Connecting students to institutions: Keys to retention and success. In M. L. Upcraft \& J. N. Gardner and Associates (Eds.), The Freshman Year Experience: Helping students survive and succeed in college (pp. 65-81). New York, NY: Jossey-Bass.

MacNeil, S., Wood, E., Zivcakova, L., Glover, R., \& Smith, P. (2014). Learning task inventories (LTIs). Exploration of optimal conditions to help students develop, improve and sustain good study and learning practices. Collected Essays on Learning and Teaching, 7(2). VIEW ITEM

Marton, F., \& Säljö, R. (1997). Approaches to learning. In F. Marton, D. Hounsell, \& N. J. Entwistle (Eds.), The experience of learning: Implications for teaching and studying in higher education ( $2^{\text {nd }} \mathrm{ed}$.). (pp. 39-59). Edinburgh: Scottish Academic Press.

Paloyo, A. R., Rogan, S., \& Siminski, P. (2016). The effect of supplemental instruction on academic performance: An encouragement design experiment. (IZA Discussion Paper No. 9696). Bonn, Germany: Institute for the Study of Labor. VIEW ITEM

Pascarella, E. T., \& Terenzini, P. T. (2005). How college affects students: A third decade of research (Vol. 2). K. A. Feldman (Ed.). San Francisco: Jossey-Bass.

Slavin, A. (2007, September 10). Has Ontario taught its high-school students not to think? University Affairs. VIEW ITEM

Tait, H., \& Entwistle, N. (1996). Identifying students at risk through ineffective study strategies. Higher education, 31(1), 97-116. VIEW ITEM
Thomas, C. R., \& Gadbois, S. A. (2007). Academic self-handicapping: The role of self-concept clarity and students' learning strategies. British Journal of Educational Psychology, 77(1), 101-119. VIEW ITEM

Tinto, V. (1993). Building Community. Liberal Education, 79(4), 16-21._VIEW ITEM

van Velzen, J. H. (2012). Teaching metacognitive knowledge and developing expertise. Teachers and Teaching, 18(3), 365-380. VIEW ITEM

Weiner, B. (1986). An attributional theory of motivation and emotion. New York: SpringerVerlug.

\section{Acknowledgements}

I would like to thank the faculty who collaborated on the targeted learning skills workshops described in this paper, and the enthusiastic students who participated in them.

\section{Biography}

Sheilagh Grills is a Learning Skills Specialist in Student Services at Brandon University. As a member of the Academic Skills Centre team, she helps students become more efficient learners through individual appointments and workshops. She also developed and teaches the transition to university success course Fundamentals of Inquiry. 